\title{
Improving the identification rate of pulmonary tuberculosis among inmates of common lodging houses
}

\author{
N J SHANKS AND K B CARROLL \\ From the Manchester Chest Clinic, Manchester M21 2RL, United Kingdom
}

SUMMARY An improvement in the identification of pulmonary tuberculosis among residents of common lodging houses has proved possible through the close co-operation of the doctor providing primary medical care, the mass miniature radiography services, and the wardens of the hostel where the proposed visit is to take place.

Renewed interest has recently been expressed about the single homeless and their place of residence-the common lodging house. ${ }^{12}$ Although the population appears to be on the increase, and is mainly confined to the inner city areas, it is by no means a new phenomenon..$^{3-5}$ The common lodging house developed in the nineteenth century, and its character has changed little over the years. The residents are mainly of Celtic or Northern origins, usually men, single, homeless, suffering from personality disorders, and socially isolated, ${ }^{6-9}$ with a high incidence of chronic alcoholism. . $^{\text {-11 }}$

The homeless form a particularly morbid subgroup ${ }^{91213}$ Half of the habituees of common lodging houses in Edinburgh ${ }^{12}$ had some form of chronic disease. Moreover, this population represents a reservoir of infection, particularly of tuberculosis, such that it could be considered a health risk to the whole community. Referrals to the chest clinics were eight times higher ${ }^{13}$ than the normal population, and $10 \%$ suffered from tuberculosis.

In Glasgow tuberculosis was found to be the fourth most common cause of death among the lodgers in the common lodging house, and the average length of survival after diagnosis was three years. ${ }^{14}$ One report $^{15}$ suggests that the streets in the immediate vicinity of a large common lodging house have a high incidence of tuberculosis.

The Joint Tuberculosis Council reported in $1965^{16}$ on the $x$-ray results of 488 residents from lodging houses at 12 co-operating centres in England, suggesting that this population had a twentyfold increased incidence of tuberculosis.

Previous attempts at locating and diagnosing such reservoirs of tuberculosis were based on surveys of common lodging houses by the mass miniature radiography services. Their success will depend on how many inhabitants accept radiography. Experience has shown a poor response. In Glasgow 860 residents of common lodging houses were invited for MMR. ${ }^{17}$ Only 193 (22\%) were $x$-rayed, of whom 67 were referred to a chest clinic. Of these, 56 attended and 22 were found to have pulmonary tuberculosis.

In Edinburgh, from 1967 to 1971, the visiting MMR managed to $x$-ray only $18 \%$ of the residents in the common lodging houses. ${ }^{18}$

\section{The study}

NJS has been providing primary medical care to this population at their place of residence. This offered a unique opportunity to examine the hypothesis that greater attendance at such surveys, and consequent follow-up, could be achieved after a good rapport had been established. Indeed, he has shown ${ }^{19}$ that reliable data can be obtained only once a meaningful relationship has been established. Such a policy was achieved not by compulsion but by tenacious persuasion, even after many failures. We attempted to improve the attendance by the following methods:

(1) Regular MMR surveys with local advertisements in the hostels, both visual and verbal.

(2) Attendances by medical personnel (NJS) at the time of the MMR survey.

(3) Results of abnormal MMR films were passed on to the authors who undertook to locate patients quickly.

(4) Patients referred to chest clinics were carefully followed up if they did not attend.

(5) All patients' appointments were supervised directly by medical staff, even at the hostel.

We applied these techniques for the whole of 1979 and then compared the attendance for MMR screening and the notifications of tuberculosis for a 
group of hostels receiving primary care (NJS), where the above measures were introduced, and a group of hostels not receiving any such extra measures. It is generally accepted by all those who have dealings with these patients that the hostels chosen for giving primary care were the worst of their sort, with few facilities for their inmates.

\section{Results}

The average nightly occupancy of the three hostels provided with primary medical care was 556 and that of the three hostels without surveillance was $\mathbf{5 4 0 .}$

Table 1 shows the number of notifications of tuberculosis for the City of Manchester and the proportion of those who were hostel dwellers. The 24 cases notified in 1979 as compared with the 15 in 1978 occurred in a period when there was an overall drop in the notification.

Table 2 gives the attendances at MMR surveys at the hostels from 1975 to 1979 . During the four years 1975-8, there were 1038 MMR attendances from the study hostels and 922 from the contrast hostels. In 1979 attendances were 682 and 185 respectively $\left.\chi^{2}=166.7, p<0.001\right)$. Notification of tuberculosis from these hostels improved as 20 out of 24 hostel cases notified in 1979 were from the study group and in 1980 nine out of 10 were from these hostels.

The numbers $x$-rayed in the study hostels increased in 1977 , which may be explained by a visit by the MMR to another hostel which has since been closed.

\section{Discussion}

The common lodging house appears to be an important reservoir of tuberculosis, and such an

Table 1 Notifications of tuberculosis, City of Manchester (1975-9)

\begin{tabular}{lllc}
\hline Year & $\begin{array}{l}\text { Total No } \\
\text { of cases }\end{array}$ & $\begin{array}{l}\text { Hostel } \\
\text { cases }\end{array}$ & $\begin{array}{l}\text { Hostel cases as } \\
\text { percentage of total }\end{array}$ \\
\hline & & & \\
1975 & 210 & 15 & $7 \cdot 1$ \\
1976 & 171 & 16 & $9 \cdot 4$ \\
1977 & 201 & 21 & $10 \cdot 4$ \\
1978 & 161 & 15 & $9 \cdot 3$ \\
1979 & 140 & 24 & $17 \cdot 1$ \\
\hline
\end{tabular}

uncontrolled focus has proved difficult to eradicate. The residents clearly cannot be relied on to undergo radiography regularly in the interest of their own health, and, generally, they have a low sense of responsibility. Inmates of lodging houses tend to resent anything of a compulsory nature, and we consider it better not to resort to compulsion but rather to persevere with sympathy and persistence. The law does, however, make provision for an unco-operative infected patient under sections 171-175 of the 1936 Public Health Act.

We recommend that MMR should visit the vagrants' place of residence every six months at a time when the largest number can be expected to be present. This can be achieved by close co-operation between the medical officer, the MMR services, and the wardens of the hostel where a proposed visit is to take place. Before this, advertisements, both verbally and visually, may increase the number who ultimately attend. Other ploys, such as the reward of free tickets in a raffle to be drawn at the end of the MMR service, have proved to be encouraging. In Edinburgh increased numbers were found to attend if attenders received a small financial reward. ${ }^{18}$

Detection of disease is of no value unless successful and acceptable treatment can be ensured. The MMR film should be read and their results sent, as soon as possible, to the medical officer, who may locate the patient before he moves on.

Certain workers ${ }^{20}$ have used a multidisciplinary team to treat this group successfully. Indeed, health visitors who are traditionally concerned with the follow-up of patients with tuberculosis are often unable to locate this type of patient. Their position is not helped by the existing poor communications between statutory and voluntary bodies working in this field. Vagrants with tuberculosis tend to percolate through the various hostels in the same town and, because of this poor communication, their place of residence remains unknown. It is only in Manchester, where a unique state of affairs exists-a doctor travelling around the different hostels-that they can be more readily detected and encouraged to accept treatment. We hope to report the results of treatment within this group in due course.

Table 2 Comparison of numbers $x$-rayed at those hostels providing primary medical care with those where there is no such provision

\begin{tabular}{|c|c|c|c|c|c|c|c|c|}
\hline \multirow[t]{2}{*}{ Year } & \multicolumn{4}{|c|}{ Primary medical care provided } & \multicolumn{4}{|c|}{ No primary care provided } \\
\hline & $\boldsymbol{A}$ & $\boldsymbol{B}$ & $\boldsymbol{C}$ & Total & $D$ & $\boldsymbol{E}$ & $\boldsymbol{F}$ & Total \\
\hline $\begin{array}{l}1975 \\
1976 \\
1977 \\
1978 \\
1979\end{array}$ & $\begin{array}{r}55 \\
24 \\
103 \\
52 \\
198\end{array}$ & $\begin{array}{r}98 \\
117 \\
103 \\
79 \\
190\end{array}$ & $\begin{array}{r}93 \\
73 \\
181 \\
60 \\
294\end{array}$ & $\begin{array}{l}246 \\
214 \\
387 \\
191 \\
682\end{array}$ & $\begin{array}{r}136 \\
111 \\
104 \\
85 \\
84\end{array}$ & $\begin{array}{l}34 \\
73 \\
26 \\
18 \\
23\end{array}$ & $\begin{array}{r}55 \\
50 \\
84 \\
146 \\
98\end{array}$ & $\begin{array}{l}225 \\
234 \\
214 \\
249 \\
185\end{array}$ \\
\hline
\end{tabular}


References

1 John HH. Primary medical care at hostels for alcoholics: a report of two surveys. Health Trends 1980; 12: 61-4.

${ }^{2}$ Shanks NJ. Care of homeless people (part 1). Update 1981 ; 1197-1202.

${ }^{3}$ Mayhew $H$. London labour and the London poor. London: Griffin, 1861.

'Booth W. In darkest England and the way out. London: Salvation Army, 1890.

${ }^{5}$ London J. People of the abyss. London: Isbister, 1903.

${ }^{\circ}$ Lodge Patch IC. Homeless men. A London survey. Proc $R$ Soc Med 1970; 63: 437-41.

${ }^{7}$ National Assistance Board. Homeless single persons. London: HMSO, 1966.

${ }^{8}$ Edwards G, Hawker A. Hensman C. Williamson V. London's skid row. Lancet 1966; i: 249-52.

${ }^{9}$ Shanks NJ. Demographic features of inmates of common lodging-houses. Manchester; University of Manchester, 1982. (MSc thesis).

${ }^{10}$ Priest RG. Homeless men. A USA-UK comparison. Proc $R$ Soc Med 1973; 63: 441-5.

${ }^{11}$ Cook T. Vagrant alcoholism. London: Trinity Press 1975.
${ }^{12}$ Scott R, Gaskell PG, Morrell DC. Patients who reside in common lodging-houses. $\mathrm{Br}$ Med J 1966; ii: 1561-4.

${ }^{13}$ Gaskell PG. Illnesses in lodging-house inmates. Health Bulletin 1969; 27: 13-7.

${ }^{14}$ Laidlaw SIA. Glasgow common lodging-houses and the people living in them. Glasgow: Corporation of Glasgow, 1956.

${ }^{15}$ Elwood PC. Tuberculosis in a common lodging-house. $\mathrm{Br}$ J Prev Soc Med 1961; 15: 89-92.

${ }^{16}$ Joint Tuberculosis Council. Tuberculosis in vagrants and inmates of lodging-houses. The Medical Officer 1965; 113: $103-4$.

${ }^{17}$ Geedes JE. Tuberculosis today. Public Health 1959; 74: 96.

${ }^{18}$ Ross JD, Reid KDG, Jamieson A. Pulmonary tuberculosis in the common hostel population. Update 1977 ; $167-74$.

${ }^{19}$ Shanks NJ. Consistency of data collected from inmates of a common lodging house. J Epidemiol Community Health 1981; 35: 133-5.

${ }^{20}$ Bunyan S, Addington WW. Baltimore tuberculosis symposium. Am Rev Respir Dis 1977; 115 : 545. 